\title{
OVERVIEW OF WORKING OF STRILING ENGINES
}

\author{
SUNNY NARAYAN ${ }^{*}$, VIKAS GUPTA ${ }^{1}$ \\ 1 “Indus International University” Una, 174301, India
}

\begin{abstract}
Engines are common devices which are important sources of power to run several devices in modern society. Many of these engines are very complex and need high levels of technological advances for smooth operations. This papers focuses on the identification, design and construction of a Stirling engine which can be easily manufactured without any special tooling or exotic materials. The underlying theory of the device is also presented and discussed with future recommendations to improve the current design.
\end{abstract}

Keywords: Stirling engines, heat transfer

\section{INTRODUCTION}

Stirling engine technology developments have been directed at a wide range of applications over the last several decades, including vehicle propulsion, gas-fired heat pump drives, aircraft propulsion, auxiliary power, and submarine power generation. The most commonly cited application for Stirling engines under development today is distributed generation for baseload or backup power. This work reveals the following technology- and design-related trends [1-3].

Most Stirling companies are developing products for residential combined heat and power (1- $5 \mathrm{~kW})$ or commercial on-site power generation $(25 \mathrm{~kW})$. Several developers are focused on niche markets that take advantage of the Stirling engine's inherent fuel-flexibility by utilizing free or inexpensive renewable fuels and heat sources, such as landfill gas, biomass waste, and industrial waste heat. EPRI Licensed Material .More than $60 \%$ of the companies investigated favor the kinematic design over the free piston design. .The majority of Stirling engines under development have operating temperatures of $1,200-1,400{ }^{\circ} \mathrm{F}$. One developer plans to operate at $2,000{ }^{\circ} \mathrm{F}$ to achieve higher thermodynamic efficiency. Alternatively, several others are designing lowto medium-temperature engines $\left(200-1,00{ }^{\circ} \mathrm{F}\right)$ in order to reduce material problems. Most Stirling engines operate at a high speed (or piston frequency). However, several companies are designing low-speed engines to reduce viscous losses and lengthen the useful life of the engine. Larger Stirling engines are more likely to have lower speeds, and smaller engines will exhibit higher speeds, similar to the trend seen in IC engines and microturbines [1-3].

\section{HEAT ENGINES}

A thermal engine is a device which converts heat energy into mechanical energy. The operation of a heat engine can be described by a simple thermodynamic cycle as follows (Figure 1) [4].

\footnotetext{
* Corresponding author, email: rarekv@gmail.com

(C) 2015 Alma Mater Publishing House
} 


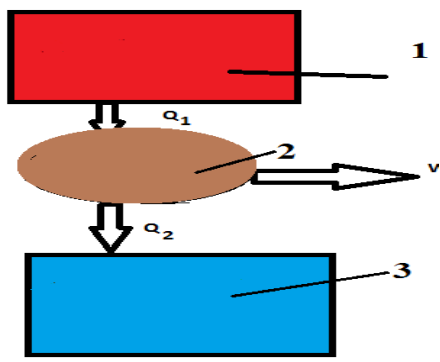

Fig. 1. The sputtering system [3]: 1 - heat source; 2 - engine; 3 - heat sink.

Heat engines can be further classified as external combustion engine or internal combustion engine. An engine where fuel is burnt outside the engine is an external combustion engine, whereas in the internal combustion engine, the fuel is burnt inside the engine. An engine operating on a Carnot or Stirling cycle is an example of an external combustion engine while one operating on an Otto or Diesel cycle is an internal combustion engine [4]. Comparison of these cycles is presented below (Table 1, Figure 2 and Figure 3).

Table 1. Comparison of various engines [5].

\begin{tabular}{|l|l|l|l|l|l|}
\hline $\begin{array}{l}\text { Type of } \\
\text { combustion }\end{array}$ & Cycle & Compression & Heat addition & Expansion & Heat Removal \\
\hline External & Carnot & Adiabatic & Isothermal & Adiabatic & Isothermal \\
\hline External & Stirling & Isothermal & Isometric & Isothermal & Isometric \\
\hline Internal & Otto & Adiabatic & Isometric & Adiabatic & Isometric \\
\hline
\end{tabular}
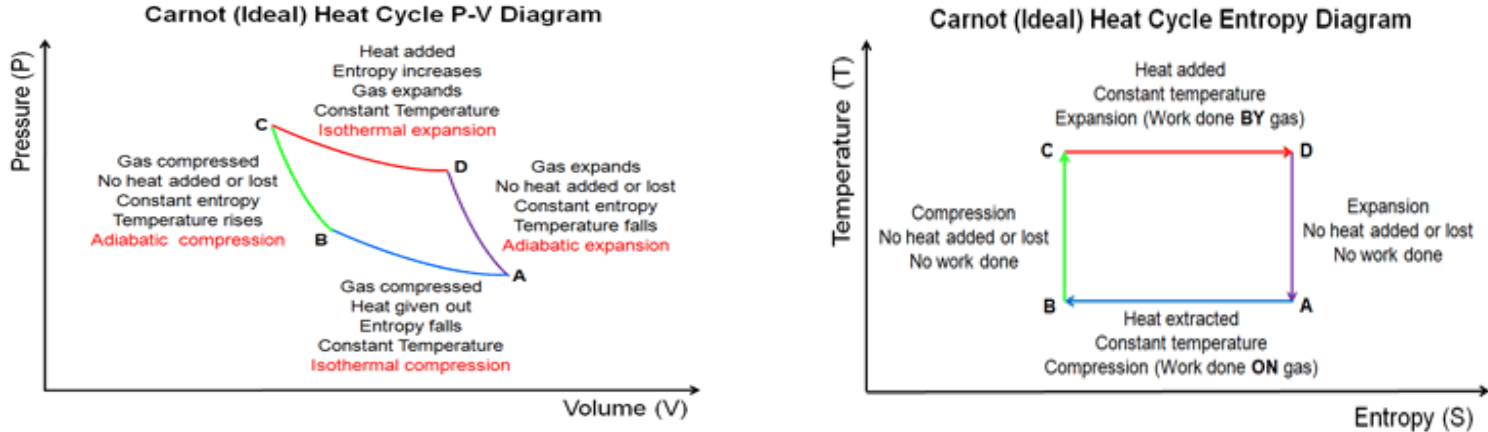

Fig. 2. P-V\& T-S plot of a Carnot cycle [5].
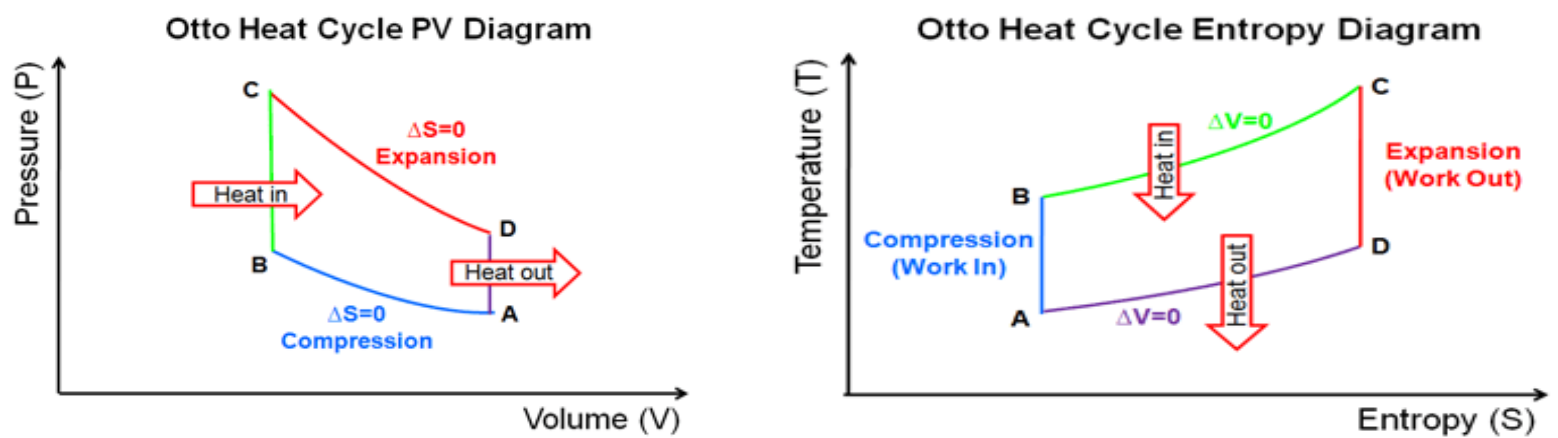

Fig. 3. P-V\& T-S plot of an Otto cycle [5].

\section{OPERATION OF STRILING ENGINE}

In a Stirling engine (Figure 4) the fluid is contained in a confined space, hence there are no problems of contamination. In order to reduce the heat losses, the mass flow rate must be low which can be maintained by low viscosity fluid or high working pressures. These engines are 30 to $40 \%$ efficient in a temperature range of 923-1073 K [6]. 


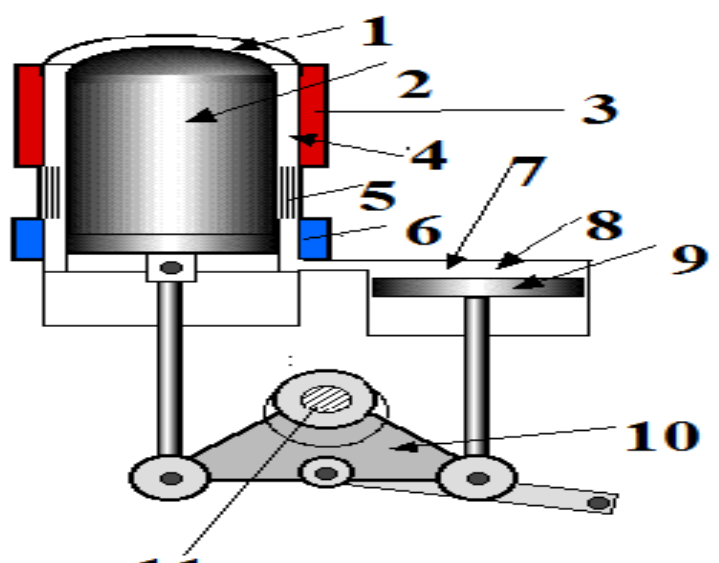

11

Fig. 4. Stirling engines: 1 - expansion space; 2 - expansion piston; 3 - heater; 4, 7 - working gas; 5 - regenerator; 6 - cooler; 8 - compression space; 9 - compression piston; 10 - ross york linkage; 11 - crank.

Regenerator is to use the waste heat from being lost to environment by storing it temporarily, thus helping to achieve high efficiencies close to an ideal Carnot cycle. A simple configuration consists of fine mesh of metallic wires. In an ideal Stirling cycle, the connecting space between hot and cold ends acts as regenerator:

1. heat sink-typically the ambient environment acts as an ideal heat sink, otherwise the cold side can be maintained by iced water or cold fluids like liquid nitrogen;

2. displacer piston-it causes the displacement of working gas between hot and cold regions so that expansion and contraction occurs alternatively for operation of engine;

3. power piston - transmit's the pressure to crankshaft.

In a Stirling engine, hot air expands when heated and contracts when cooled. This principle of operation was most properly understood by Irish scientist Robert Boyle from his results on experiments on air trapped in a $\mathbf{J}$ shaped glass tube.

Boyle stated that temperature of a gas $(\mathrm{T})$ is inversely proportional to its volume and product of pressure $(\mathrm{P})$ and volume $(\mathrm{V})$ occupied is a constant depending on temperature of gas.

\section{Hence PV=NRT}

where $\mathrm{N}$ is number of moles and $\mathrm{R}$ is universal gas constant.

Various assumptions are made in this cycle are [7]:

1) working fluid is an ideal gas;

2) conduction and flow resistance is negligible;

3) frictional losses are neglected;

4) iso-thermal expansion and contraction.

This cycle can be described by following stages (Figure 5) [7]:

1) Phase C-D: Iso-thermal expansion - the working fluid undergoes an iso-thermal expansion absorbing the heat from source. The power piston moves out, hence increasing the volume and reducing the pressure. The work done in expansion of gas is given by:

$$
\mathrm{We}=\mathrm{RT} \log \left[\frac{V_{D}}{V_{C}}\right]=\mathrm{nRT}_{\mathrm{c}} \log \left[\frac{V_{D}}{V_{C}}\right]
$$

2) Phase D-A: Power piston now reaches the outermost position and stays there so that volume is constant. The working fluid is passed through the regenerator where it gives up heat for use in next cycle. Hence its temperature and pressure falls. No work is done during this phase. 
3) Phase A-B: The power piston stats moving inwards, reducing its volume and increasing its pressure the working fluid gives up heat to cold sink. The work done in compressing the gas is given by:

$$
\mathrm{Wc}=\mathrm{RT} \log \left[\frac{V_{B}}{V_{A}}\right]=\mathrm{nRT}_{\mathrm{H}} \log \left[\frac{V_{B}}{V_{A}}\right]
$$

4) Phase 2-3: The power piston is at its most inwards point and stays there to keep volume constant. Working fluid passes again through the regenerator, recovering the heat lost in $2^{\text {nd }}$ phase, hence its pressure and temperature goes up.

$$
\text { Wnet }=\mathrm{We}-\mathrm{Wc}=\mathrm{nR}\left[\mathrm{T}_{\mathrm{H}}-\mathrm{T}_{\mathrm{c}}\right]\left[\frac{V_{\max }}{V_{\min }}\right]
$$

but $\mathrm{V}_{\mathrm{B}}=\mathrm{V}_{\mathrm{C}}, \mathrm{V}_{\mathrm{A}}=\mathrm{V}_{\mathrm{D}}$

Hence engine efficiency $(\eta)$ can be expressed in form of:

$$
\begin{aligned}
& \frac{\mathrm{nR}\left[T_{H}-\mathrm{Tc}\right]\left[\frac{V_{\text {max }}}{V_{\text {min }}}\right]}{\mathrm{nR}\left[T_{H}\right]\left[\frac{V_{\max }}{V_{\text {min }}}\right]} \\
& \eta=\frac{T_{H}-T_{C}}{T_{H}}
\end{aligned}
$$

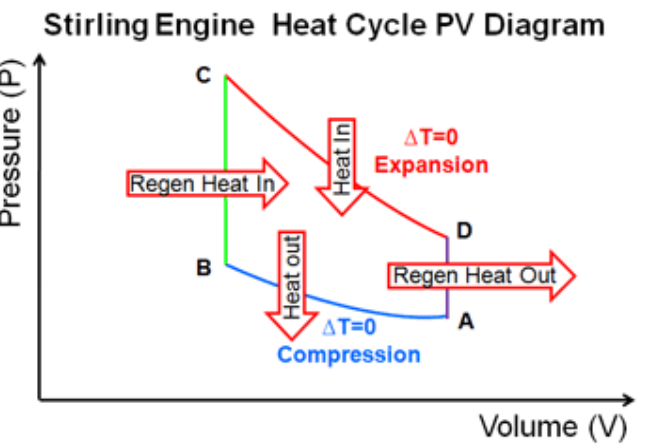

Stirling Engine Heat Cycle Entropy Diagram

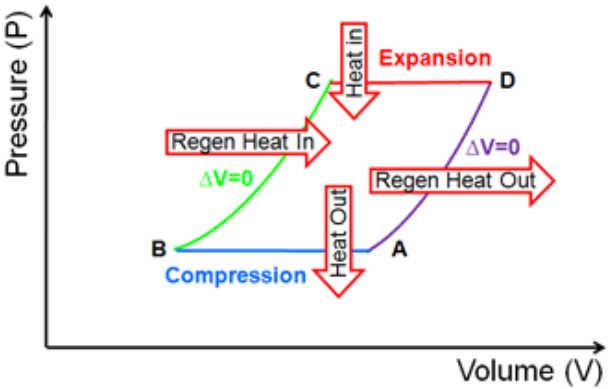

Fig. 5. P-V \& T-S plot of a Stirling cycle [5].

In Stirling cycle, two Isochoric processes replace the two iso-entropic processes $\mathrm{s}$ in an ideal Carnot cycle. Hence more work is available than a Carnot cycle as net area under P-V curve is more. Thus there is no need for high pressures or swept volumes. This can be seen in the Figure 6.
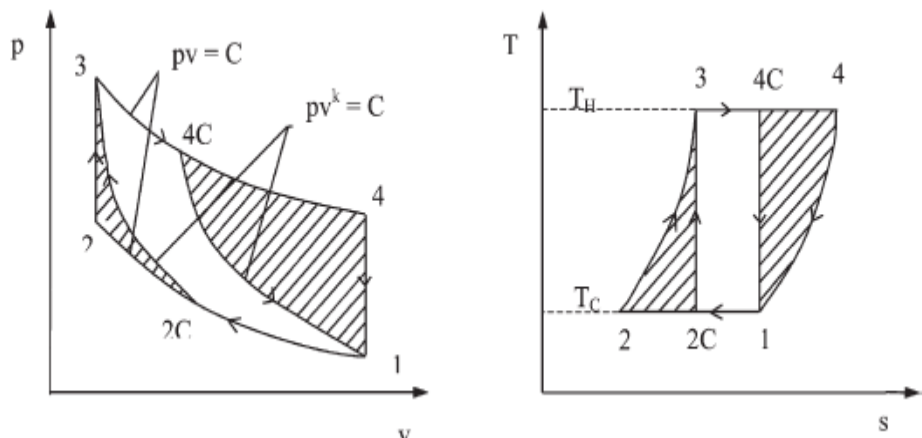

Fig. 6. Comparison of Stirling cycle and Carnot cycle [5]. 


\section{TYPES OF ENGINES}

Stirling engines can be further classified as alpha, beta or gamma type (Figure 7). Alpha version consists of two power pistons in series with heat sink, heat source and regenerator [8].

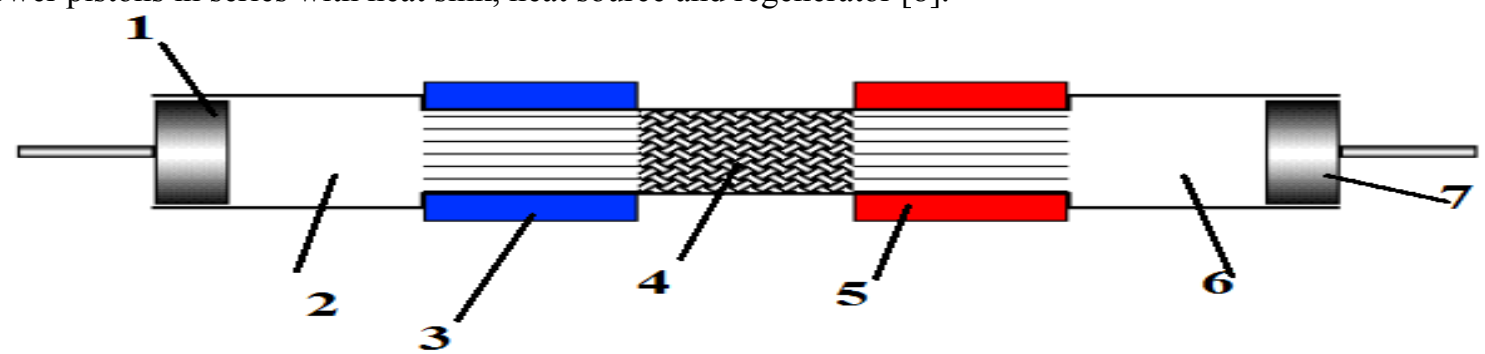

Fig. 7. An Alpha Stirling engine configuration: 1 - Compression piston; 2 - Compression space; 3 - Cooler; 4 Regenerator; 5 - Heater; 6 - Expansion space; 7 - Expansion piston.

\subsection{Working of a Alpha Stirling engine}

This engine consists of following stages:

1) Expansion-working gas is present in hot side and gains heat expanding, hence pulling both pistons inwards (Figure 8) [8].

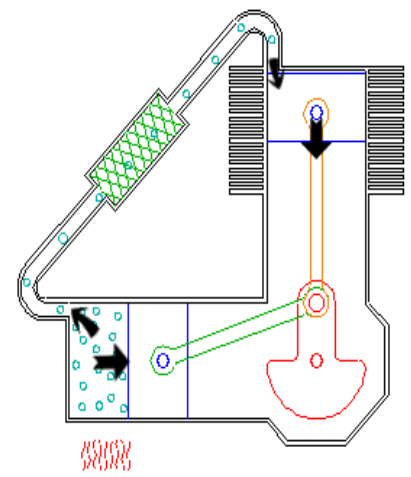

Fig. 8. Working stages of a Alpha Stirling Engine.

2) Transfer Motion of crank shaft transfers most of the gas from hot side towards the cold side (Figure 9).

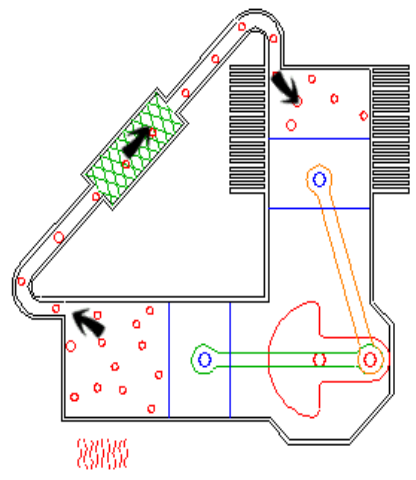

Fig. 9. Working stages of a Alpha Stirling Engine.

3) Contraction-Working gas is transferred towards cold side, cools and contacts pushing both pistons outwards (Figure 10). 


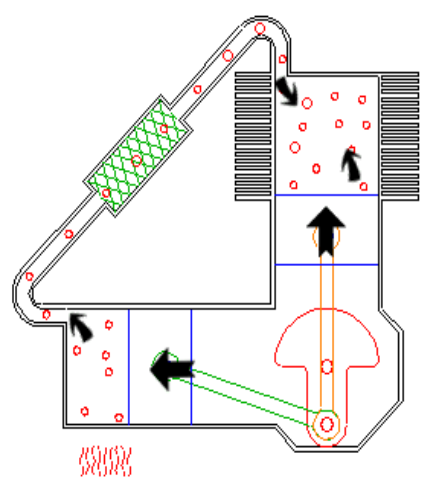

Fig. 10. Working stages of a Alpha Stirling Engine.

4) Transfer-Motion of crank shaft through $90^{\circ}$ causes transfer of gas again to hot side so that cycle is repeated again (Figure 11).

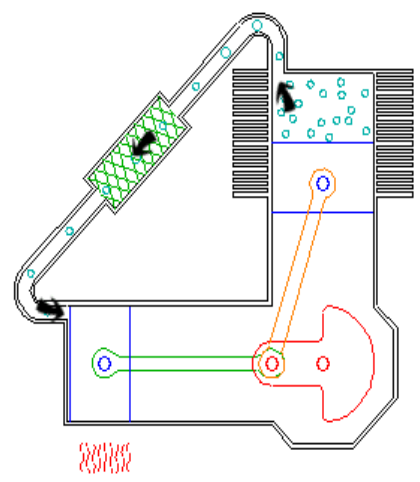

Fig. 11. Working stages of a Alpha Stirling Engine.

\subsection{Working of a Beta Stirling engine}

Beta type engine and gamma type engine have a single power piston, whereas alpha type engine have two power pistons [9]. Beta type Stirling engine (Figure 12) has both power and displacer pistons on the same axis whereas in gamma configuration, both pistons are separate. Gamma engines are best suited for studies whereas Beta ones are difficult to fabricate.

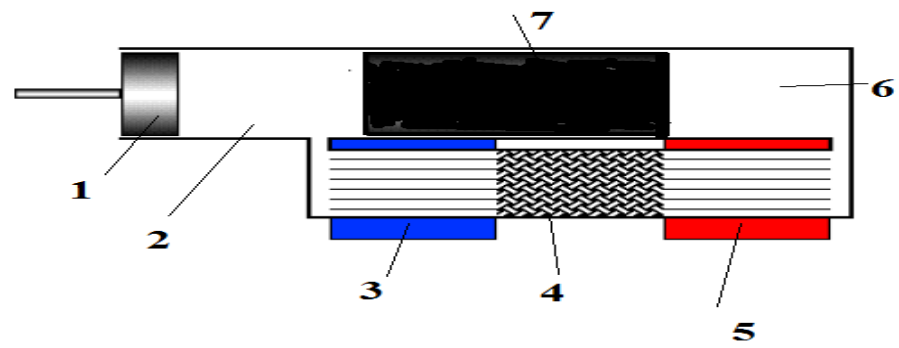

Fig. 12. An Alpha Stirling engine configuration: 1 - compression piston; 2 - compression space; 3 - cooler; 4 regenerator; 5 - heater; 6 - expansion space; 7 - expansion piston.

Working of a beta engine can be understood in following cycles:

1) Expansion-most of the gas is at the hot end, which gains heat and expands (Figure 13);

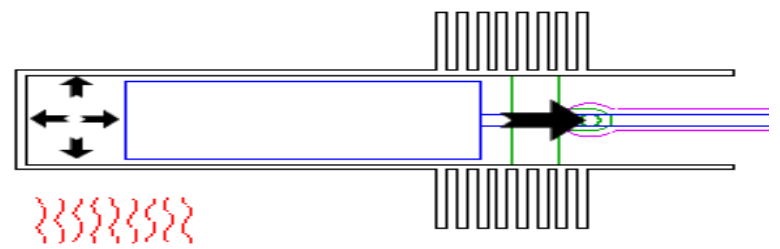

Fig. 13. Working stages of a Beta Stirling Engine. 
2) Transfer-motion of fly wheel causes gas to move towards cold end passing over the displacer (Figure 14);

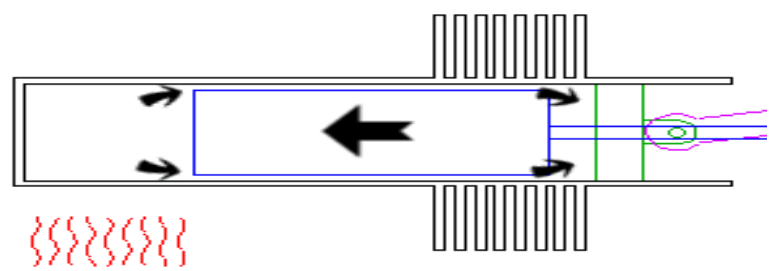

Fig. 14. Working stages of a Beta Stirling Engine.

3) Contraction-most of the gas is in cold end where it cools and contracts drawing piston inwards (Figure 15);

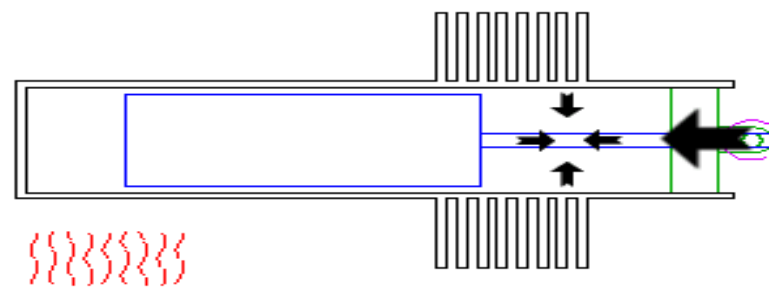

Fig. 15. Working stages of a Beta Stirling Engine [9].

4) Transfer-motion of flywheel causes displacer to move out, transferring gas again to hot end (Figure 16 and Figure 17).

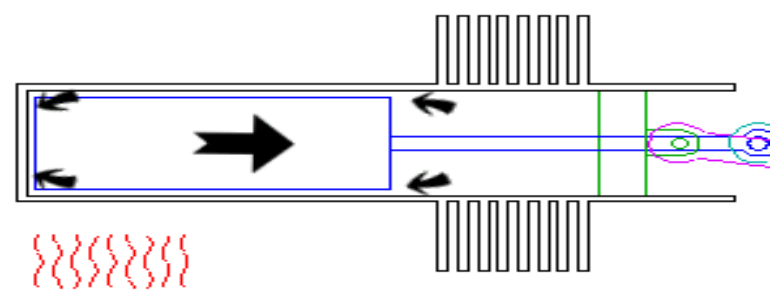

Fig. 16. Working stages of a Beta Stirling Engine [9].

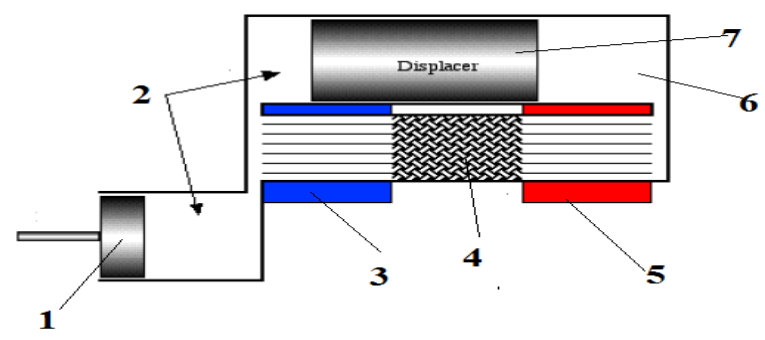

Fig. 17. Gamma Stirling engine configuration: 1 - compression piston; 2 - compression space; 3 - cooler; 4 regenerator; 5 - heater; 6 - expansion space; 7 - expansion piston.

\section{WORKING GAS}

It is a gas on which engine operates [10]. There are several gases that can be used to run a Stirling engine. Lighter gases having atomic mass lesser than that of air have higher specific heat and gas constant and lower viscosity resulting in lesser viscous losses and higher heat storing capacity [2].This can be seen in the following graph which was obtained by simulation by Philip Brothers (Figure 18) [11-14]. 


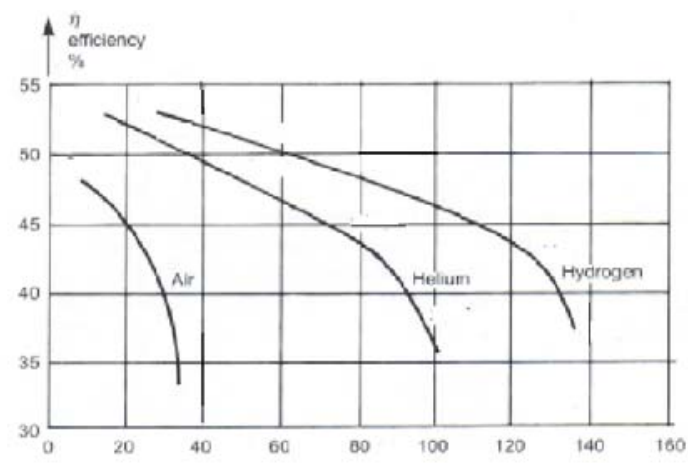

Fig. 18. Stirling engine efficiency V/S power output for various gas.

\section{CONCLUSIONS}

Stirling engines can be run on wide variety of fuels including solar energy without need for fuel to come in contact with operating gas hence avoiding containment. Hence even if solar energy is unavailable, alternative fuels can be used for operations Thus these devices are not susceptible to fuel shortage. Further noise less operations are possible. Hence suitable for submarines. Lower maintenance is needed and combustion of fuel occurs outside the engine. These engine can be redeveloped as a combined heat and power unit as seen seen in Figure 19.

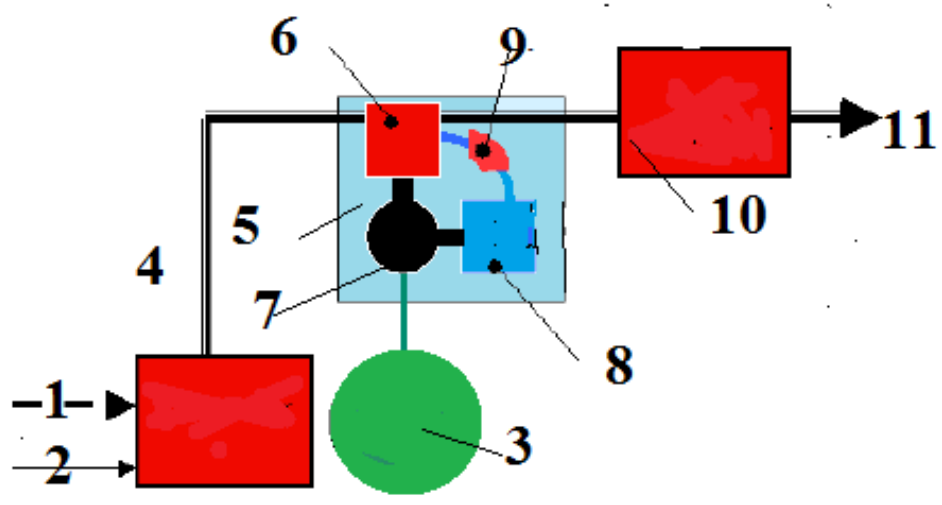

Fig. 19. An combined heat and power unit configuration: 1 - fuel; 2 - air; 3 - combustor; 4 - exhaust gas; 5 Stirling heater; 6 - boiler heat exchanger; 7 - generator; 8 - cooler heat exchanger; 9 - regenerator; 10 - heat exchanger; $11-$ consumer.

\section{REFERENCES}

[1] Narayan, S., Gupta, A., Ranjeet, R., Performance analysis of liquid piston fluidyne systems, Mechanical Testing \& Diagnosis, vol. 2, 2015, p. 12-18.

[2] Narayan, S., Analysis of noise emitted from diesel engines, Journal of Physics: Conference Series. IOP Publishing, vol. 662, no. 1, 2015, p. 1-9.

[3] Gupta, A., Sunny, N., Effects of turbo charging of spark ignition engines, Hidraulica, vol. 4, 2015, p. 62-65.

[4] http://www.mpoweruk.com/heat_engines.html (23.03.2014).

[5] Nedelcu, D., Ghican (Bostan), A., The calculation of the pelton and francis turbine hill chart using the HydroHillChart software, HIDRAULICA, no. 4, 2015, p. 7-16.

[6] Narayan, S., Designing of liquid piston fluidyne engines, Hidraulica, no. 2, 2015, p. 18-26.

[7] Narayan, S., Gupta, V., Motion analysis of liquid piston engines, Journal of Engineering Studies and Research, no. 2, vol. 21, 2015, p. 71-78.

[8] Asnaghi, A., Ladjevardi, S.M., Saleh Izadkhast, P., Kashani, A.H., Thermodynamic performance analysis of solar Stirling engine, 2 May 2012, ISRN Renewable Energy, Tehran, Iran, p. 1-14. 
[9] Stirling engines - Mechanical Configurations, Ohio University, https://www.ohio.edu/mechanical/stirling/ engines/engines.html, Apr. 2010, (23.03.2014).

[10] Beta type Stirling engines, Ohio University, https://www.ohio.edu/mechanical/stirling /engines/beta.html, N.p., Apr. 2010. (23.03.2014).

[11] Gupta, V., Ranjeet, S., Narayan, S., Motion analysis of fluidyne engines, Technical journal, vol. 9, no. 3, 2015, p. 242-244.

[12] Rana, R., Gupta, A., Narayan, S., Design of liquid piston engine system, Tribological Journal, vol. 5, 2015, p. 153 - 157.

[13] Rana, R., Gupta, A., Narayan, S., Review of Stirling engine system, Tribological Journal, vol. 5, 2015 , p. 146-153.

[14] Narayan, S., A review of diesel engine acoustics, FME Transactions, vol. 42, 2014, p. 150-154. 